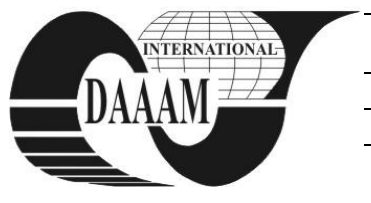

\title{
DETERMINATION OF INSPECTION POINT BASED ON PROCESS COSTING METHODOLOGY
}

\author{
TEERAVARAPRUG, J[irarat]
}

\begin{abstract}
This paper utilizes the concept of process costing methodology to determine an inspection point of a process. All incoming inputs are assumed to fall in the acceptable ranges of before production inspection processes. Two more inspection processes are required. They are during production and after production inspection processes. This paper gives an attempt to determine the inspection point of during production in order to minimize average unit cost. Two types of unit costs are considered. They are material and conversion costs. An average unit cost model is proposed and utilized in a numerical example. Based on the example, it shows that an appropriate inspection point should be about at the middle of the process and the point seems to be insensitive to material costs and the probabilities of passing the inspection processes.

Key words: inspection, process costing
\end{abstract}

\section{INTRODUCTION}

Costing is an important process that many companies engage in to keep tracks of where their money is being spent in the production and distribution processes. One type of costing system that is used in certain industries is process costing. Process costing is one of the methodologies that traces and accumulates direct costs, and allocates indirect costs of a manufacturing process (Shim \& Siegel, 2009). Process costing methodology is appropriate for companies that are massproduced in a continuous fashion. Therefore, the process costing methodology is used frequently in industries.

Costs of producing products can be divided into two types, which are material cost and conversion cost. Material cost, in this case, means direct material, which can be easily identified with the unit of production. For example, the cost of glass is a direct materials cost in light bulb manufacturing (Lanen et al., 2008). Conversion cost is the costs of converting raw materials into products and it is the combination of direct labor costs plus manufacturing overhead costs. In a process, direct materials may be added in a lump sum at a point in the production process. This research assumes that direct materials are added at the beginning of the production process. Conversion costs (direct labor plus overhead) are normally assumed that the costs considered to be added uniformly in proportion to how complete the units are. This research is also used the assumption.

Inspection is an appraisal activity that compares goods or services to a standard. Inspection can occur at three points: before production, during production, and after production. The logic of checking conformance before production is to make sure that inputs are acceptable. The logic of checking performance during production is to make sure that the conversion of inputs into outputs is proceeding in an acceptable manner. The logic of checking conformance of output is to make a final verification of conformance before passing goods on the customers (Stevenson, 2007). This research assumes that the incoming materials or inputs are acceptable and considers only during production and after production inspections.
This research combines the concept of process costing methodology to determine an appropriate inspection point (during production inspection point). A mathematical model is proposed. A numerical example is used to illustrate the model. Finally, an analysis of selecting an inspection point is given.

\section{THE SITUATION}

In a continuous process, all materials are inspected to ensure that they are in the acceptable ranges of conformance. Then the materials are added in to the process. This paper assumes that the materials are added in a lump sum at the beginning of the process. To transform the materials to finished products, labor and overhead costs are required. The summation of labor and overhead costs is called conversion cost. Conversion costs (direct labor plus overhead) are normally assumed that the costs considered to be added uniformly in proportion to how complete the unit is. A during production inspection process is exist. This paper tries to determine an inspection point of a during production inspection process. In the inspection process, the on-going product would be continuously produced if the conformance is in an acceptable manner. On contrary, if the conformance is out of an acceptable manner, the on-going product is scrapped. After production inspection process exists in order to verify the product conformance before passing them on the customers. Fig. 1 shows the illustration of the situation. The question is then where the during production inspection process should be added. It is assumed that all reject items are scrapped.

$\begin{array}{cc}\begin{array}{c}\text { Before production } \\ \text { inspection }\end{array} & \begin{array}{c}\text { During production } \\ \text { inspection }\end{array}\end{array}$

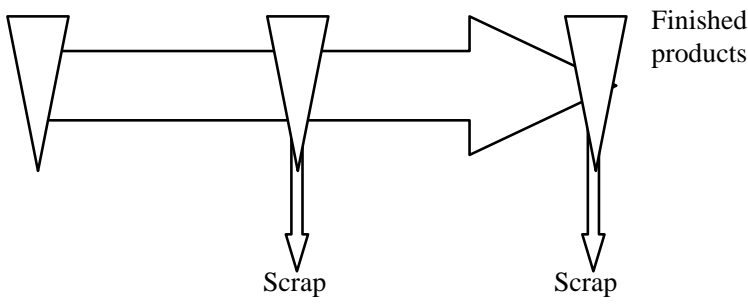

$0 \%$ $100 \%$

Fig. 1 The situation 


\section{NOTATIONS AND MODEL}

The notations used in this research are shown in Table 1.

\begin{tabular}{|l|l|}
\hline Variable & Descriptions \\
\hline$U C$ & Unit cost \\
\hline$C_{M}$ & Material cost per unit \\
\hline$P_{C}$ & $\begin{array}{l}\text { Process percentage from beginning to the during } \\
\text { production inspection process }\end{array}$ \\
\hline$C_{C}$ & Conversion cost per unit \\
\hline$C_{I 1}$ & The during production inspection cost \\
\hline $\operatorname{Pr}_{1}$ & $\begin{array}{l}\text { Probability of passing the during production } \\
\text { inspection process }\end{array}$ \\
\hline$C_{I 2}$ & \begin{tabular}{l} 
The after production inspection cost \\
\hline $\operatorname{Pr}_{2}$
\end{tabular}$\quad \begin{array}{l}\text { Probability of passing the after production } \\
\text { inspection process }\end{array}$ \\
\hline
\end{tabular}

Tab. 1. Notations

To calculate average unit cost, two types of costs are considered: material and conversion costs. Normally, a unit uses $C_{M}$. When passing the during and after production inspection processes, some of units are rejected and scrapped. The material cost of scrapping units should be counted in the costs of passing units. If $\mathrm{Pr}_{1}$ and $\mathrm{Pr}_{2}$ are probabilies of passing the during and after production inspection process, the average material cost per unit is $C_{M} /\left(\operatorname{Pr}_{1} * \operatorname{Pr}_{2}\right)$. Similarly, the average during production inspection cost is $C_{I 1} /\left(\operatorname{Pr}_{1} * \operatorname{Pr}_{2}\right)$.

To calculate the average conversion cost, the process is divided into two phases: before and after during production inspection processes. The conversion cost of before production inspection process equals $P_{C} C_{C}$. Again, when passing the inspection processes, some of units are rejected and scrapped. The conversion costs incurred to those units should be included into the passing units. Therefore, the average conversion cost of the first phase is $P_{C} C_{C} /\left(\operatorname{Pr}_{1} * \operatorname{Pr}_{2}\right)$. The conversion cost of the second phase equals $\left(1-P_{C}\right) * C_{C}$ and again the average conversion cost of this phase when considering the rejected units is $\left[\left(1-P_{C}\right) * C_{C}\right] / \operatorname{Pr}_{2}$. Similarly, the average after production inspection cost is $C_{I 2} / \mathrm{Pr}_{2}$. Therefore, the average unit cost is the summation of average material cost, during production inspection cost, average conversion cost, and average after production inspection cost. The average unit cost can be modeled as shown in equation below.

$$
U C=\frac{\left(\left(C_{M}+P_{C} C_{C}+C_{I 1}\right) / \operatorname{Pr}_{1}+\left(1-P_{C}\right)\left(C_{C}\right)+C_{I 2}\right)}{\operatorname{Pr}_{2}}
$$

This research gives an attempt to determine an appropriate during production inspection point, which is $P_{C}$, that minimizes the unit cost $(U C)$.

\section{NUMERICAL EXAMPLE}

This research attempts to minimize the unit cost above. It is assumed that material and conversion costs per unit are 100 and 200 , respectively. The during and after production inspection costs are 30 and 50. Probabilities of passing the during and after production inspection processes are 0.8 and 0.95 . It is found that the appropriate point of inspection is at the zero percentage or at the beginning of the process. But actually, at the beginning of the process, a before production inspection process is given. All inputs are acceptable. Therefore, at that point, there should not be a defective item. Defective items should be amplified as the process percentage increased. It is then assumed in this numerical example that the probability of passing the during production inspection process $\left(\mathrm{Pr}_{1}\right)$ is $1-P_{C} / 2$ and the probability of passing the after production inspection process ( $\left.\operatorname{Pr}_{2}\right)$ is $1-\frac{\left(1-P_{c}\right)}{2}$. The appropriate inspection point is at 55 percentage of the process and the unit cost becomes 607.78. By changing $P_{C}$ and $C_{M}$, the result shows in Tables 2-3. It can be seen that the appropriate inspection point is insensitive to the change of material costs. In the case that $\operatorname{Pr}_{1}$ and $\operatorname{Pr}_{2}$ become $1-P_{C} / 3$ and $1-\frac{\left(1-P_{c}\right)}{3}$, the appropriate point is 56.75 percentage. It can be concluded that the appropriate inspection point is quite insensitive.

\begin{tabular}{|l|l|}
\hline$P_{C}$ & $U C$ \\
\hline 0.1 & 705.26 \\
\hline 0.2 & 664.82 \\
\hline 0.3 & 636.20 \\
\hline 0.4 & 617.86 \\
\hline 0.5 & 608.99 \\
\hline 0.6 & 608.93 \\
\hline 0.7 & 618.10 \\
\hline 0.8 & 637.04 \\
\hline 0.9 & 666.99 \\
\hline
\end{tabular}

Tab. 2. Relations of $P_{C}$ and $U C$

\begin{tabular}{|c|c|c|c|c|c|}
\hline$C_{M}$ & $U C$ & $P_{C}$ & $C_{M}$ & $U C$ & $P_{C}$ \\
\hline 10 & 447.58 & 0.56 & 100 & 607.79 & 0.55 \\
\hline 20 & 465.38 & 0.56 & 200 & 785.73 & 0.54 \\
\hline 30 & 483.19 & 0.56 & 300 & 963.63 & 0.54 \\
\hline 40 & 500.99 & 0.56 & 400 & 1141.5 & 0.53 \\
\hline 50 & 518.79 & 0.55 & 500 & 1319.35 & 0.53 \\
\hline 60 & 536.59 & 0.55 & 600 & 1497.19 & 0.53 \\
\hline 70 & 554.39 & 0.55 & 700 & 1675.02 & 0.52 \\
\hline 80 & 572.19 & 0.55 & 800 & 1852.84 & 0.52 \\
\hline 90 & 589.99 & 0.55 & 900 & 2030.65 & 0.52 \\
\hline 100 & 607.79 & 0.55 & 1000 & 2208.46 & 0.52 \\
\hline
\end{tabular}

Tab. 3. Relations of $C_{M}, U C$ and $P_{C}$

\section{DISCUSSIONS}

The paper uses the concept of process costing methodology to determine an appropriate setting of inspection point during production while assuming that the before production and after production inspections are utilized. The numerical example shows that the inspection point should be about the middle of the production process. Moreover, the inspection point seems to be insensitive to the changes of material costs and the probabilities of passing the inspection processes.

\section{REFERENCES}

Shim, J. K. \& Siegel, J. G. (2009), Modern Cost Management and Analysis 3rd Ed. Barron's Education Series, Inc

Lanen, W. N., Anderson, S., \& Maher, M. W. (2008). Fundamentals of Cost Accounting, McGraw Hill

Stevenson, W. J. (2007), Operations Management, 9th Ed, McGraw-Hill, New York 